THE CAROLINA MANTIS BY C. FEw sErss.

One of the most peculiar of orthopterous insects found hence, when hard pressed, it seeks safety in digging a new hole, and very often succeeds in thus escaping; but when this horse" (mantis Carolina, Linnæus). It will easily be re- resource fails, the animal rolls its head and legs under its cognized among other insects by its large, spiny, raptorial stomach, forming a ball like a hedgehog, and thus incased fore legs or arms. With these it captures its prey, which in armor defies the teeth or claws of its adversary. It is distinct American floras, each characteristic of immense consts entrely of insects. While devouring a its fore legs, which are strongly toothed o ens, which are strongly to When holding the insect to its mouth while eating, I have often thought it had a half human appearance, like a child devoid of tabl etiquette, with the end of a turker's leg in each hand, te from the femur.

The mantis is savage in its habits, and they often have fierce combats among themselves. They rush to the attack with their raptorial legs elevated and wings expanded; but when the most expert of the two combatants ha once firmly seized its adversary, they fold their wings and fight with tooth and claw. I have on two instances witr.essed the victorious mantis partially devour the vanquished adversary.

The mantis does not merely "suck the blood" of its prey, as stated by a popula entomologist, but it generally devours blood, internal organs, and shell, especially if the object be a soft bodied insect. In the case of a caterpillar, if it should be a hairy species. the hair and skin are generally rejected.

In September the female attaches a cluster of eggs (Fig. 2) to the limb of a tree, or to the rail of a fence. Here they remain until

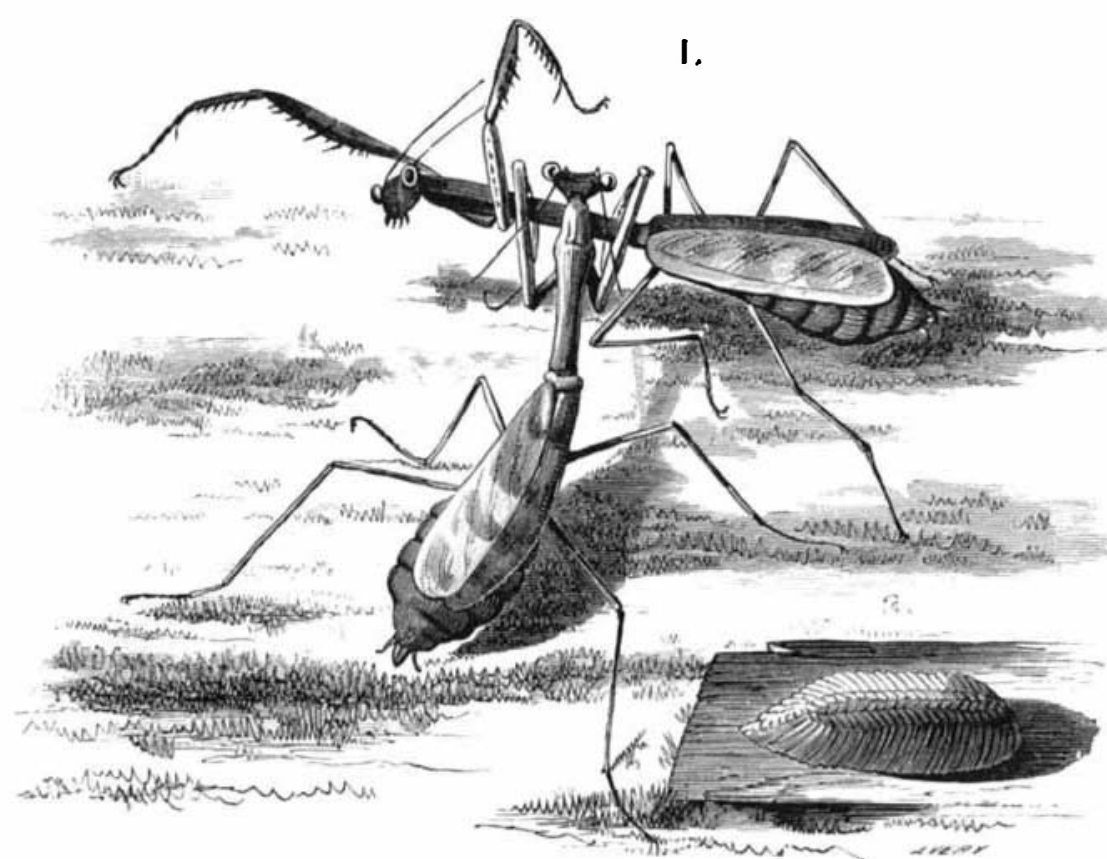

THE CAROLINA MANTIS.
Botany or the Rocky Mountalns,

Sir Joseph Hooker, a distinguished botanist of London ccompanied Dr. Hayden in the survey of Colorado and Utah. He has given in Nature some notes on the botany f the Rorky Mountains, which we copy. The section cold or mountain floras, namely, (1) a prairie lora derived from the eastward; (2) a socalled desert and saline flora derived from the west; (3) a sub-alpine, and (4) an alpine flora. Two of the principal American regions are in a broad sense humid; one, that of the Atlantic const and which extends to the Mississippi river, the other, that of the to the Macieric Wester Ocean, andwo inland the Western Ocean, and two inland, that of the northern part of the continent, extending to the polar regions, and that of the southern part, extending through New Mexico to the Cordillera of Mexico proper. The -getation of the middle latitudes of the continent resolves itself into three principal meridional floras, incomparably more diverse than those presented by any similar meridians in the Old World, being, in fact, as far as the trees, shrubs, and many genera of herbaceous plant are concerned, absolutely distinct. These are the two humid and the dry intermediate regions above indicated.

Each of these again is subdivisible into three, as follows: (1.) The Atlantic slope plus Mississippi region, subdivisible into an Atlantic, a Mississippi valley, and an interposed mountain region with a temperate and sub-alpine flora. (2.) The Pacific slope, sub-

the following summer, when the young mantes hatch out. |mole and other subterranean animals, the eyes are of minute divisible into a very humid cool forest-clad coast range; the I take the following from my journal: A pril 9, 1877.-The $\mid \begin{aligned} & \text { mole and other subterranean animals, the eyes are of minute } \\ & \text { dimensions, and are hidden under the soft and profuse fur }\end{aligned}$ great hot drier Californian valley, formed by the San Juan eggs of the mantis Carolina, sent me from Baltimore in of the face.

November last, hatched to-day. "The young mantes escape only from the upper, longitudinally, central portion of the convex sub-ovoid egg-cluster. They work themselves out by moving backward and forward and from side to side. Their legs are closely folded to the body when they emerge, giving them the appearance of a lárge gnat larva, and it and finally a solution of $1 \frac{1}{3}$ gms. of tannin in 15 gms. 作 river flowing to the north and the Sacramento river flowing
south, both into the Bay of San Francisco; and the Sierra south, both into the Bay of San Francisco; and the Sierra
Nevada flora, temperate, sub-alpine, and alpine. (3.) The Tinted Paper.

Tinted paper may be prepared in any desirable shade as Rocky Mountain region, subdivisible into a prairie flora, a follows: $1 \mathrm{gm}$. of any aniline color is dissolved in $30 \mathrm{gms}$. desert or saline flora, a Rocky Mountain proper flora, tem. strong alcohol, 300 gms. of distilled water are added, perate, sub-alpine, and alpine.

The difference between the floras of the first and second of these regions is absolute; not a pine or oak, maple elm, 作 ( whestern, and defence when disturbed. When they quit the egg, they leave a small thin shell behind them, adhering to the egg case. The young mantes, when just hatched, are of a pale brown color; their legs and head pale green, the former with dull brown bands.above the joints; their eyes are dark and prominent; their bodies linear: the abdomen but little. wider than the thorax; no vestiges of wings visible. They become came much darker in color after several hours' exposure to the sun. Each little in length. They drankgreedily from drops of water which were sprinkled about the board upon which they were sunning themselves, throwing back their antennæ to prevent them becoming wet.

From sixty to seventy individuals came from each egg-cluster. As the egg pack. ets were kept in a warm room during the ets were kept in a warn room during winter, their hatching was accelerated, and consequently the coming forth of the young mantes was premature. Theylived
only a few days, being killed by the coldonly a few days, bein

ness of the weather.
The specimens from which I made my The specimens from which I made my drawing, and also the egg packet, were procured in Baltimore, Md., where it is common enough; but I have never met with it in the vicinity of Philadelphia.

\section{THE TRUNCATED PICHCIAGO.} The "truncated pichiciago" is one of the smallest of four-footed animals. It is not more than two inches in length. The shield which covers the entire upper portion of its body is composed of a single piece, and consists of reguiar, uniform and smooth scales. neatly arranged like mosaic. This coat of mail is truncated vertically at its rear portion. The animal has a curious cut-off appearance owing to the apparent absence of a tail, but in real. ity due to the position of that member. ity due to the position of that member.
which is short and closely pressed against

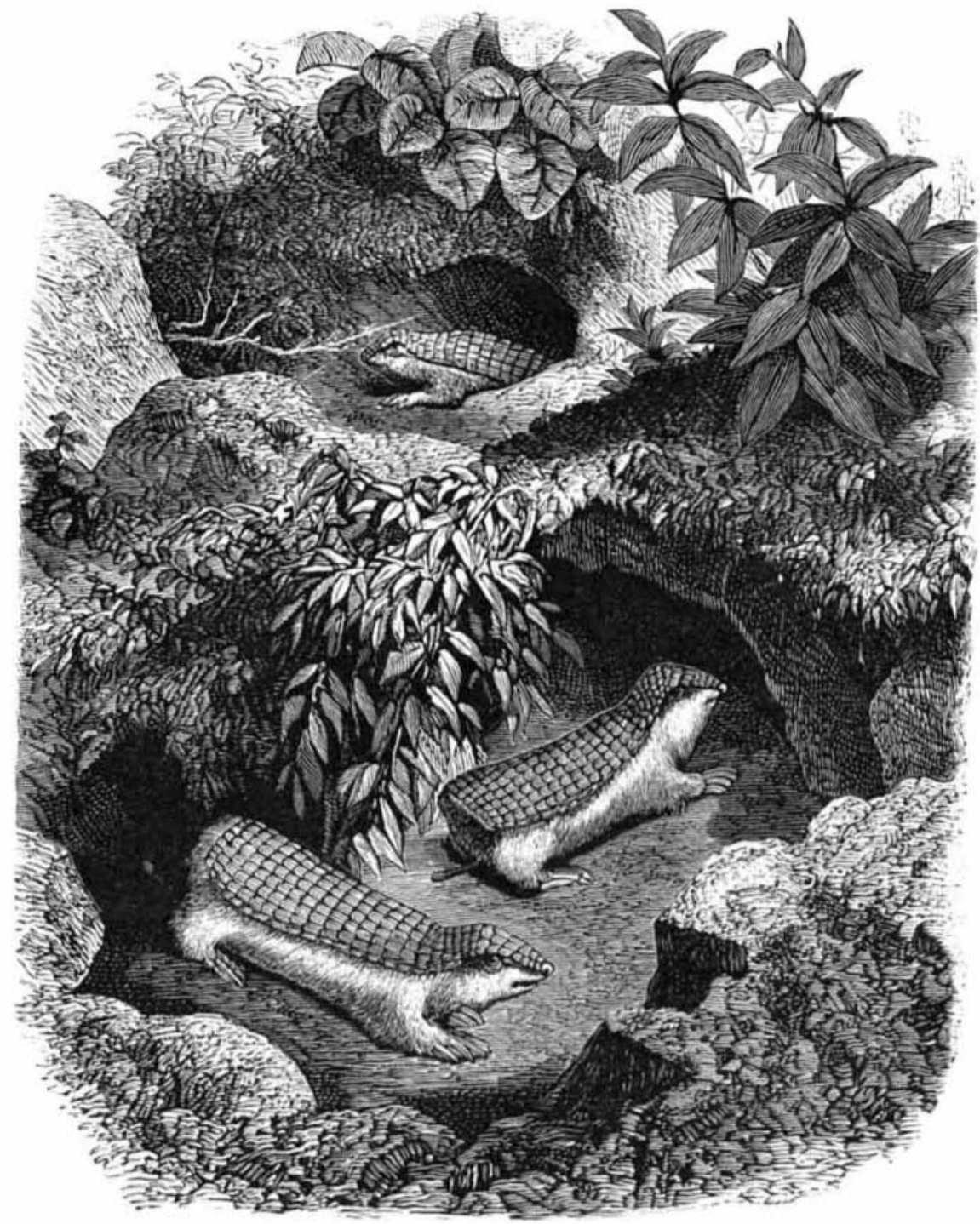

THE TRUNCATED PICHICIAGO. , though abundantly distinct from both, has a few ele-
ments of the eastern region, and still more ments of the easter
of the western.

\section{Magnetic Nickel,}

The magnetic properties of pure nickel have been lately investigated by $M$. Wild, of St Petersburg, who procured a nickel magnet in the form of a flat pointed bar, made by Wharton, in Philadelphia. The results are as follows: 1 . Pure nickel takes, as compared with the behavior of pure soft iron, a considerable quantity of per manent magnetism; but the maximum of this is only a half to a third of the perma nent magnetism which may be acquired by hard steel. 2. The magnetism remaining in nickel after cessation of the magnetizing force is less permanent than in well hardened steel; the rradual loss of well hardened stee ing and cooling is in nickel greater than in hard steel, even when, by repeated heating and cooling it has, like steel, been brought to a certain state of permanence. 3. The temperature co-efficient of nicke magnets in the latter state is less than that of well hardened steel. 4. The temporary magnetism which pure nickel acquires is about double its permanent magnetic moment, half of the temporary magnetion which hard steel can acquire, and a fourth of that which soft iron can acquire. In its magnetic behavior, nickel is thus throughout subordinate to steel and iron.

Dangers of Galvanizers, Waste.

Pollution of streams by manufacturers refuse has been assigned as the cause of more evils than can be fairly brought home to it. A new charge has been brought against it, not only of serious pecuniary waste, but also of great and increasing danger to life and property. It appears that the galvanizers of the Wolverhampthe body. All the lower portions, the neck, stomach, sidest |izontal lines by means of a small eponge. The paper is.then ton district, England, are in the habit of discharging their and legs are covered with long and fine hairs. $\quad$ hung up to dry, and may be covered after a few days with waste acid into the sewers. The damage caused by thi The pichiciago is found chiefly in the Cordilleras moun- a concentrated solution of sodium silicate, to every 100 practice is almost incredible; but it is clearly proved that tains, in Chili, where it feeds on earth worms, snails, and parts of which 10 parts of glycerin have been added, if it the sewers themselves are being rapidly destroyed; the irriinsects. It uses its long, large, and sharp nails to make is desired to impart to it a gloss. burrows, which are often very deep. In these it remains concealed during the greater part of the day, and rarely venures to wander to any great distance even by night. It can

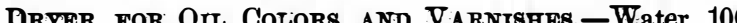
gation farms which dispose of the sewage are being renthe surroundin ing canals, are rapidly corroded.-Ironmonger. 